\title{
Knowledge co-production in tourism and the process of knowledge development: Participatory action research
}

Tramy Ngo, Gui Lohmann and Rob Hales

\begin{abstract}
This chapter provides insights from a knowledge co-production study, that utilised a constructivist paradigm, on collaborative marketing for the business sustainability of community-based tourism enterprises. Based on participatory action research (PAR), the process of developing knowledge through the involvement of various research stakeholders in different stages of the research process is investigated. The lessons learnt from applying knowledge co-production approach through PAR in a tourism study are presented. In addition, implications for further research to develop this methodology within the realm of tourism are suggested.
\end{abstract}

Keywords: constructivism, knowledge co-production, PAR, knowledge development process, collaborative marketing, CBTEs.

\section{Introduction}

Community-based tourism enterprises (CBTEs) are micro-scaled, rural and remote arealocated businesses where the local community is the owner, the manager and the main beneficiary. Although CBTEs have proliferated in less developed countries because of their potential to transform sustainable tourism objectives into actions, only a few CBTEs can claim to be successful (Goodwin \& Santilli, 2009; Rocharungsat, 2008). Most CBTE projects experience market failure and collapse after the initial funding period (Dixey, 2008; Mielke, 2012). In studies of CBTEs, a collaborative approach is widely advocated to help CBTEs overcome their marketing challenges and shift their businesses towards long-term success (Dodds, Ali \& Galaski, 2016; Idziak, Majewski \& Zmyślony, 2015; Mbaiwa, Stronza \& Kreuter, 2011). Accordingly, there is a need to develop a collaborative marketing approach to underpin stakeholder relationships in marketing co-efforts for the business sustainability of CBTEs. The development of such an approach necessitates the involvement of multiple stakeholders with different perspectives. To this end, collaborative forms of knowledge generation are 
proposed (Carr, Ruhanen, \& Whitford, 2016; Torres-Delgado \& Saarimen, 2014). In particular, where subaltern viewpoints and marginalised voices are involved, these should be integrated into knowledge generation (Chambers \& Buzinde, 2015). Owing to the recognition of different forms of knowledge (Berkes, 2009), knowledge co-production approach is appropriate to frame the development of a collaborative marketing approach for CBTE sustainability. The knowledge co-production approach is governed by the constructivist paradigm and is facilitated in research processes through participatory action research (PAR) (Castleden Morgan, \& Lamb; 2012; Espeso-Molinero, Carlisle \& Pastor-Alfonso, 2016).

\section{Constructivism as a research paradigm}

A research paradigm consists of "the basic belief system or worldview that guides the investigator, not only in the choice of the method but in ontological and epistemological fundamental ways" (Guba \& Lincoln, 1994, p. 105). A research paradigm reflects the standpoints of researchers regarding ontological, epistemological, and methodological stances. Accordingly, a research paradigm underpins the involvements of researchers and research participants in the research process, the tools and techniques of data collection and analysis, the interpretation of research outcomes, and the evaluation of research contributions. According to Guba and Lincoln (1994), the selection of a specific research paradigm is dependent on the answers to ontological, epistemological and methodological questions, which include, "What is the form and nature of reality and, therefore, what is there that can be known about it?"; "What is the nature of the relationship between the knower or would-be-knower and what can be known?"; and "How can the inquirer (would-be-knower) go about finding whatever he or she believes can be known?". Answering the ontological question determines the answers to the epistemological and methodological questions and shapes a selected research paradigm.

As the domain of collaborative marketing for the business sustainability of CBTEs involves CBTE stakeholders of diverse viewpoints and the study on this topic involves researchers and practitioners from different ways of knowing, a constructivist approach is adopted as the research paradigm. The constructivist approach, according to Guba (1990), admits the multiple realities that exist in the minds of the "insiders" and attempts to obtain one or a few constructions that are reconciled from different perspectives. Multiple realities co-exist 
because of the interpretation of perspectives belonging to different cosmologies. A constructivism-based study should focus on the values constructed at the inter-sphere of different perspectives. It is argued that this paradigm effectively supports the investigations of highly contextualised problem domains, in which different worldviews co-exist and might be incongruent with each other (Hollinshead, 2006). Owing to such the potential of the constructivist approach in reconciling diverse viewpoints and prioritising the values of knowledge, the approach is advocated in this study. The approach enables a harmonising platform for the diverse viewpoints of CBTE stakeholders and co-researchers interacted and compromised, through which the research goal of co-proposing a sustainable marketing approach for the long-term success of CBTEs in less-developed countries is fulfilled. Based on the constructivist paradigm, a co-construction approach to knowledge generation is adopted to guide the research process. The knowledge co-production approach and its applications in the research stages are illustrated in the rest of this chapter.

\section{Knowledge co-production in tourism research}

Knowledge co-production refers to an interactive approach to knowledge generation whereby researchers and research participants interact and influence each other to different degrees in generating knowledge, and so, the nature of the knowledge is considered to be socially constructed knowledge (Dale \& Armitage, 2011). Knowledge co-production is based on the premise that knowledge generation is an outcome of collaborative interactions among researchers and research participants. Researchers possess evidence-based perspectives in the academic world, whereas research participants represent diverse viewpoints of the social world. Knowledge co-production allows a research participant to reconcile his or her perspectives with those of others. New knowledge is developed through interactions between researchers and research participants. The new knowledge is characterised by its dual attributes of scientific validity and social relevance (Nowotny, 2003). Moreover, in the realm of knowledge co-production, each research participant is both a knowledge generator and a social learner (Berkes, 2009; Dale \& Armitage, 2011; Pohl et al., 2010). Here, participants co-generate knowledge through interactions and concomitantly experience a social learning process through their interactions. 
Castleden et al. (2012) argue that five attributes define a knowledge co-production study. First, both researchers and research participants share ownership in establishing the study's direction and process stages. The researchers should be flexible in experimenting with different research approaches throughout the research process. Second, the perspectives of both researchers and research participants are regarded as legitimate sources of knowledge. Data collected from the research participants are regarded as an independent school of thought without being subjugated to scientific knowledge. Third, reflexive learning among researchers and research participants is promoted. Fourth, new knowledge is co-generated. Fifth, new knowledge is disseminated in accordance with the culture, values, and beliefs of the viewpoints involved to obtain mutual benefits. The practice of these five attributes in a study enables the abovementioned potential of the knowledge co-production approach to be achieved.

The application of a knowledge co-production approach in tourism studies is increasing. Most of the tourism studies using the knowledge co-production approach focus on sustainability; they include natural resource management, climate change adaptation and destination sustainability. For instance, numerous studies investigate the significance of the knowledge co-production approach in the management and governance of natural resources in tourist destinations (see Marshall, Viegas, Frey, \& Ribeiro, 2016; Ungar \& Strand, 2012). Climate change adaptation for destination sustainability is another domain in which the knowledge co-production approach is employed (see Armitage, Berkes, Dale, Kocho-Schellenberg, \& Patton, 2011). The emergence of the knowledge co-production approach within the broad discipline of sustainability can inform tourism studies. Nevertheless, few tourism studies have used the knowledge co-production approach (Becken, Zammit, \& Hendrikx, 2015; EspesoMolinero et al., 2016). Moreover, the scarcity of tourism research using the knowledge coproduction approach contrasts with the recurrent call for its application in tourism studies (Carr et al., 2016; Chambers \& Buzinde, 2015).

A majority of knowledge co-production studies focus on the significance of this approach in terms of integrating two different ways of knowing, i.e., Indigenous knowledge and scientific knowledge, for the benefit of collaborative knowledge. Current knowledge co-production studies investigate collaborative works between Western-based knowledge and Indigenous 
knowledge (Armitage et al., 2011; Davidson-Hunt \& Michael O'Flaherty, 2007; Weiss, Hamann, \& Marsh, 2013) and between intellectual works in the North and those in the South (Castleden et al., 2012; Chambers \& Buzinde, 2015). However, there are an absence of studies illustrating the potential of a knowledge co-production approach for harmonising practitioner standpoints and researcher viewpoints. This paucity is in contrast to the recent burgeoning of tourism studies arguing for the capacity of the knowledge co-production approach in bridging the research-practice gap (Dredge \& Jamal, 2015; Font \& McCabe, 2017). Additionally, owing to its acknowledgement of different standpoints and appreciation of the voices of the marginalised, the knowledge co-production approach has the potential to reconcile diverse perspectives in collective efforts. However, it remains an under-utilised approach on the tourism agenda. Thus, by conducting a case study in the domain of CBTE collaborative marketing for business sustainability, we argue that the knowledge coproduction approach can responsively address diverse perspectives in collaborative works, shorten the research-practice gap, and thereby contribute to the discussion of knowledge coproduction in the tourism context in a positive and constructive way that will benefit all stakeholders.

At a different level, although many studies investigate the significance of knowledge cogeneration in terms of problem-solving (Marshall et al., 2016; Ungar \& Strand, 2012) and the outcomes of the knowledge co-production process (Becken et al., 2015; Espeso-Molinero et al., 2016; Holmes, Grimwood, King, \& Lutsel, 2016), less attention has been paid to illustrating how to develop knowledge through collaborations among knowledge holders. The knowledge development process should encompass the generation of socially constructed, value-based knowledge through interactions among research stakeholders while including those stakeholders' reflections on their learning experience throughout the process. We attempted to address this gap by interrogating the process of knowledge development in a knowledge co-production study focused on CBTE collaborative marketing.

Accordingly, the PAR approach was employed in the investigation process to achieve the aim of this study. PAR is a useful tool for learning promotion and knowledge co-generation (Kindon, Pain, \& Kesby, 2007; Reason \& Bradburry, 2008), and therefore, is an important part of the knowledge co-production process. More specifically, PAR provides a methodological 
framework for exploring diverse perspectives on CBTE collaborative marketing, bringing them together for knowledge interactions and evaluating learning outcomes achieved through an action learning cycle. Hence, we were confident that the utilisation of PAR complimented and extended our ontological constructivist stance.

\section{PAR in the knowledge co-production study of CBTE collaborative marketing}

\section{Participatory action research}

PAR is an integrated paradigm of participatory approaches and action-oriented research. More specifically, PAR refers to an inquiry-based approach in which relevant participants in a research project change and improve a problem by actively examining it together (Kindon et al., 2007). Through this research process, researchers and research participants jointly produce knowledge that is understandable, actionable, and accessible to them. Thus, participant collaboration and knowledge co-production shape the PAR methodology.

In PAR, the research process is designed through recurring stages of research, action and reflection, as illustrated in Table 1 (Kindon et al., 2007). PAR values two types of research outcomes. First, the collective actions and quality information generated are counted as research contributions. Second, the self-mobilisation of research participants in terms of skills, knowledge and capacities throughout the research experience is also evaluated (Kindon et al., 2007). Following this process, collaborative methods and research implementation techniques are employed. Aligning with the flexibility and non-coercive nature of PAR, methodological techniques are very diverse. These techniques can be based on traditional tools such as interviews, and focus groups, and on innovative tools using technology; for instance, diagrams and videos (Kindon et al., 2007). Method selection is context-based and considers research participants' capabilities and resources. Flexible research contributions in PAR and diverse methodological tools reinforce the prevalence of PAR in the tourism literature. 
Table 1: Stages of the PAR process

\begin{tabular}{ll}
\hline Stages & \multicolumn{1}{c}{ Activities } \\
\hline Research & The research participants identify a context-pertinent problem that \\
& needs to change. \\
Action & The research participants interact and arrive at a set of actions for \\
& change or improvement. \\
& The set of actions is aligned with research participants' capabilities \\
& and is context-plausible \\
Reflection & The research participants experience learning and reflection during \\
& the action implementation
\end{tabular}

(Source: Adopted from Kindon et al., 2007)

PAR as a methodological framework for knowledge development in the knowledge coproduction study of CBTE collaborative marketing

In the realm of tourism, PAR has been used extensively in sustainable tourism research (Cole, 2006; Idziak et al., 2015). PAR is regarded as an effective approach to integrating different viewpoints and multiple disciplines in sustainable tourism, fostering the potential to achieve sustainable tourism in practice and at the grassroots level. The method has been utilised to empower the Indigenous communities, which are conventionally viewed as marginalised in the tourism planning process (see Cole, 2006; Idziak et al., 2015). It is also recognised that PAR facilitates individual and social changes towards sustainability orientations (see Jamal \& Watt, 2011). The implications of PAR for empowering marginalised voices in the research process and facilitating learning outcomes for participants validate its potential as a base framework to assess the knowledge co-production process.

Indeed, the process of knowledge development through harmonising diverse perspectives in developing a responsive collaborative marketing approach for CBTE's business sustainability can be facilitated by PAR. First, the acknowledgement of diverse viewpoints in PAR allows different types and sources of knowledge to be voiced in the process of knowledge coproduction. PAR arguably amplifies the voices of research participants, specifically those of Indigenous knowledge holders. Accordingly, Indigenous knowledge is recognised and actively 
engaged in co-generating new knowledge. Second, it is argued that PAR's action-based principle facilitates knowledge interactions, which remain central to the knowledge coproduction process. The interactions of different types and sources of knowledge are used to achieve a new socially constructed, value-based knowledge that embraces the viewpoints of different knowledge holders. Third, the PAR attribute of learning through engagement paves the way to assessing learning experiences, as reflected by both the researchers and the research participants in the knowledge co-production process. Thus, PAR is used to construct a research design, as illustrated later in this chapter, to explore the process of knowledge development through the collaborative works of researchers and CBTE stakeholders in different stages of the study of CBTE collaborative marketing for business sustainability.

\section{Research context}

The context of this study is CBTEs in Vietnam. Specifically, based on the purposive sampling method, three CBTEs in Vietnam were approached: Triem Tay Floating Restaurant, Thanh Toan Gardening and Cookery, and Minh Tho Homestay. These CBTEs represent different development models and diverse marketing approaches of CBTEs in Vietnam. Table 2 provides background information on the investigated CBTEs. 
Table 2: Background information of the investigated CBTEs

\begin{tabular}{|c|c|c|c|c|c|}
\hline Case study & & & Location & & Characteristics \\
\hline Triem & Tay & 0 & Triem Tay Village, Quang Nam & O & Was launched in June 2015 \\
\hline Floating & & & Province & ○ & Is owned by a Kinh ${ }^{[1]}$ family \\
\hline Restaurant & & $\circ$ & $\begin{array}{l}3 \mathrm{~km} \text { from Hoi An City, a } \\
\text { tourist centre }\end{array}$ & ० & $\begin{array}{l}\text { Received support from the International } \\
\text { Labour Organisation (ILO) and UNESCO }\end{array}$ \\
\hline & & $\circ$ & $\begin{array}{l}\text { The village is facing out- } \\
\text { migration issues due to land }\end{array}$ & & $\begin{array}{l}\text { for technical training, field trips, } \\
\text { marketing and promotion, etc. }\end{array}$ \\
\hline & & & erosion (ILO, 2015) & ○ & $\begin{array}{l}\text { Offers food and beverage packages and } \\
\text { boating experiences }\end{array}$ \\
\hline & & & & ○ & $\begin{array}{l}\text { Is a member of Triem Tay's CBTE co- } \\
\text { operative }^{[2]} \text {, which was established in } \\
\text { September } 2015\end{array}$ \\
\hline Thanh & Toan & $\circ$ & Thanh Toan Village, Thua & ○ & Was established in 2012 \\
\hline Gardening & and & & Thien Hue Province & ○ & Is owned by a Kinh family \\
\hline Cookery & & & & ○ & Was formerly supported by the Japan \\
\hline & & ० & $8 \mathrm{~km}$ from Hue City, a tourist & & International Corporation Agency (JICA), \\
\hline & & & centre & & SNV, followed by the ILO and UNESCO \\
\hline & & ○ & The village is renowned for & $\circ$ & Services include gardening experience \\
\hline & & & Thanh Toan Tile-Roofed & & and cooking classes \\
\hline & & & Bridge, a National Heritage & & \\
\hline & & & Site and a tourist attraction & & \\
\hline & & & & & $\begin{array}{l}\text { Currently in partnerships with 2-3 tour } \\
\text { operators }\end{array}$ \\
\hline & & & & ○ & $\begin{array}{l}\text { Is a member of Thanh Toan's CBTE co- } \\
\text { operative }\end{array}$ \\
\hline
\end{tabular}

\footnotetext{
${ }^{[1]}$ The Kinh people are the majority ethnic group of Vietnam

${ }^{[2]}$ The CBTE co-operative is a form of community alliances that specialises in tourism. This co-op is a community institution consisting of member CBTEs and acting as a representative of the member entrepreneurs. Usually, a committee of selected members is responsible for the management of the co-op. In Vietnam, CBTE co-ops, similar to other communal cooperatives, are legally integrated into the over-arching Vietnam Cooperative Alliance, a non-profit organisation whose purpose is to support members through consulting, training, and providing a voice for policy change.
} 


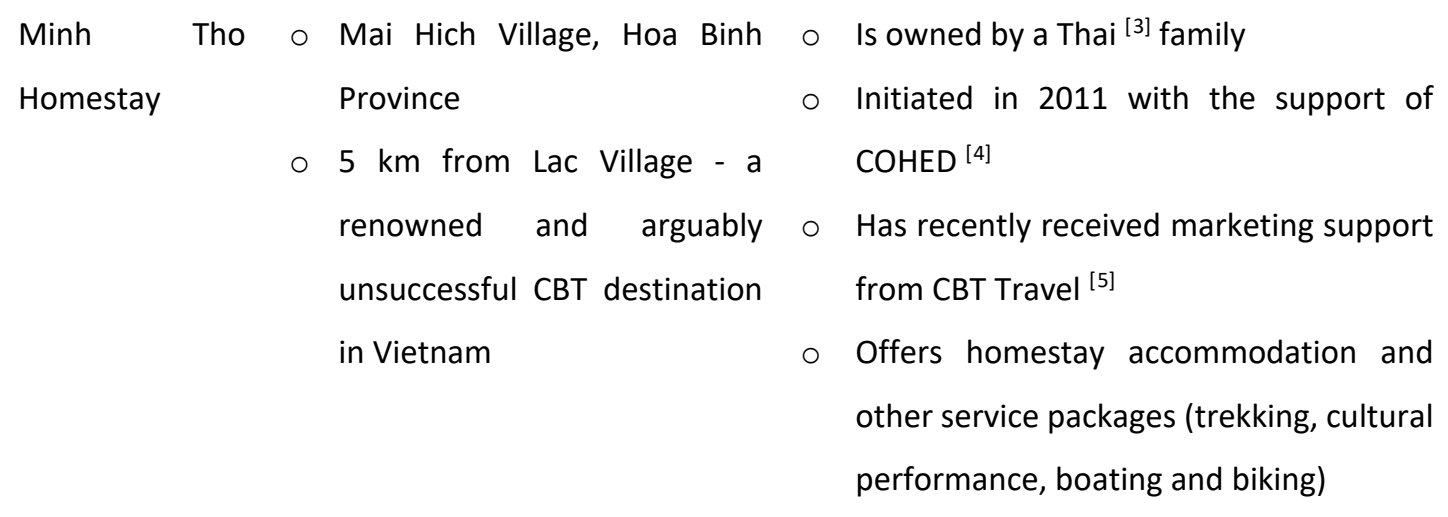

(Source: Authors)

\section{Research design}

The research was designed in associations with the knowledge development process framed by the three-stage PAR exemplar of Kindon et al. (2007). The knowledge development process began with a knowledge exploration stage, followed by knowledge interaction and then a knowledge reflection stage before proceeding to the next process. Along with this process, the research design consists of two stages. Figure 1 visually presents the linkages between the knowledge development process underpinned by PAR and the stages of the research design.

\footnotetext{
${ }^{[3]}$ The Thai people are one of the minority ethnic groups of Vietnam

${ }^{[4]}$ COHED: Centre for Community Health and Development

${ }^{[5]}$ CBT Travel is a travel agency specialising in CBT products and services in Vietnam, self-labelled as a social enterprise. It initiated the approach "franchised CBT" approach. Under this approach, CBT Travel facilitates CBT initiatives (mostly homestays) equipped with standard facilities and services to fulfil travellers' needs. The projects are then handed over to local entrepreneurs through franchising partnerships in which CBT Travel is responsible for sales, marketing and service quality control related to the projects. At the time of the investigation, CBT Travel supported Minh Tho Homestay with sales and marketing.
} 
Figure 1: Knowledge development process included in the research design

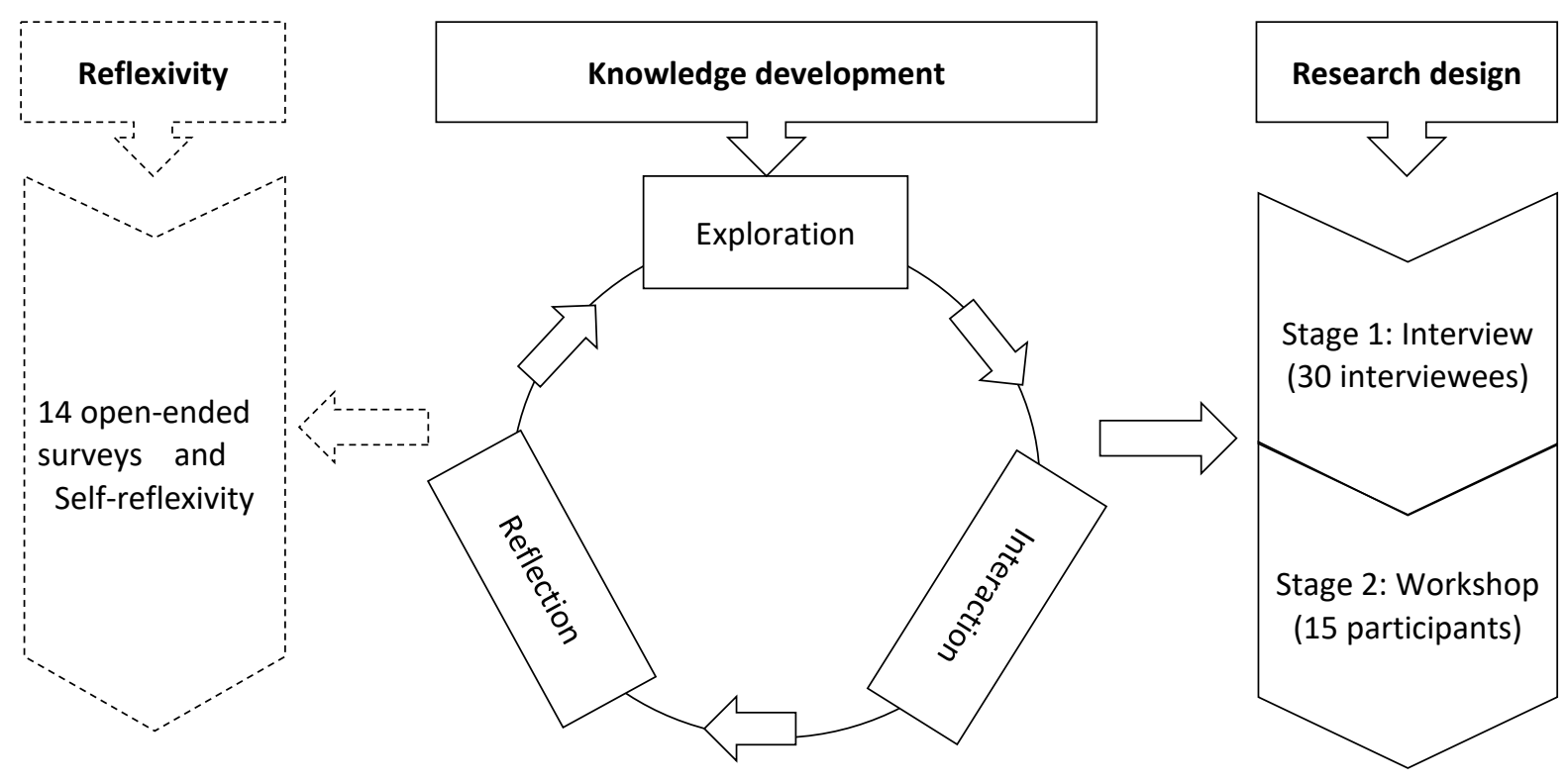

(Source: Adopted from PAR process of Kindon et al., 2007)

Stage 1 - Interviews

The perspectives of CBTE stakeholders regarding CBTE collaborative marketing alternatives and marketing proposals for CBTE sustainability were investigated. To address this objective, the interviewing method was adapted. Thirty key stakeholders directly involved in the three CBTEs were identified as interview respondents through the purposive sampling method and snowball techniques. Respondents were asked about their viewpoints related to who is included in and who facilitates a CBTE marketing network, the factors of success for CBTE collaborative marketing and how such an approach leads to the business sustainability of CBTEs. They were also asked about a proposal of marketing strategies oriented towards CBTE long-term success. The interviews were conducted face-to-face in public places at the convenience of the respondents in the period from November 2015 to January 2016.

Content analysis and narrative analysis were utilised to interpret the interview data. As a result, collaborative marketing alternatives for the business sustainability of CBTEs shaped by stakeholders from different perspectives and categories were elucidated. From these 
collaborative marketing alternatives, the incongruence of perspectives on CBTE collaborative marketing emerged.

\section{Stage 2 - Workshop}

At this stage, stakeholders with different perspectives communicated to explore other perspectives and obtain a shared understanding regarding a collaborative marketing approach for the business sustainability of CBTEs. Knowledge interaction occurred on a platform that can be established using collective learning tools. In this study, a group discussion was selected to facilitate knowledge interactions (Barbour, 2008). Because of time and budget limitations, the group discussion took the form of a half-day workshop.

Major tasked in workshop planning included setting the day, time, venue of the workshop and incentives for workshop participants and inviting participants and maintaining their interest in the workshop. As the workshop involved multiple stakeholders from both the public and private sector, Friday morning was suggested as the most appropriate day. Additionally, the community hall was deemed the best option to serve as the workshop's venue, given that the workshop was about CBTEs, collaborative marketing and business sustainability. Regarding the participation incentives, workshop participants were offered the option of pre-arranged one-night accommodation or an equivalent amount of cash to maximise their likelihood of attending. As a result, the workshop was held on the morning of 17 March 2017 in the community hall of Triem Tay Village, Quang Nam province, Vietnam.

Regarding the workshop participants, thirty interview respondents were targeted with an invitation email or phone call. The email or phone call specified the workshop objectives, i.e., sharing interview outcomes and discussing CBTE collaborative marketing issues that emerged from the interviews. Only five invitees out of thirty accepted the invitation. Three other participants suggested sending representatives to participate in the workshop. Considering a desired group discussion size of eight to 12 participants (Jennings, 2010; Krueger \& Casey, 2014), the recommendations of participants who had accepted, and the need to have representatives of all categories of CBTE stakeholders, three additional participants were invited. Overall, eleven people accepted invitations to participate. Unexpectedly, four participants, who had heard about the workshop expressed interest in attending and were 
accepted because the workshop's purpose was to obtain and share knowledge. Therefore, fifteen people ultimately participated. Following the invitations, various activities were conducted to maintain the participants' interest in the workshop. In particular, a video briefly summarising the interview outcomes and introducing the workshop objectives was sent to participants two weeks before the workshop. An infographic detailing the collaborative marketing alternatives was sent to the participants one week after the video.

The workshop was conducted in the form of roundtable discussions to facilitate a power-free environment for all voices (Ross et al., 2015). Participants discussed the explanation behind diverse perspectives on CBTE collaborative marketing and negotiated with each other to finalise a common understanding of the topic. Participants were also provided with a proposed marketing strategy tailor-made for CBTE sustainability in Vietnam for a review and feedback.

\section{Reflexivity}

Participation in knowledge interactions during the research process is regarded as a learning process that generates learning outcomes for involved participants (Berkes, 2009; Maiello, Viegas, Frey \& Ribeiro, 2013). Thus, both the first researcher and the research participants were expected to learn applicable knowledge by "trading-off" with other perspectives. Tools for evaluating the learning experience were identified through surveying the workshop participants and the self-reflexivity of the main researcher. Fourteen surveys were distributed to participants at the end of the workshop as one participant left before the workshop ended. Concomitantly, the first author recalled the transformation in her epistemology, research skills and new insights owing to her entanglement throughout the research process. In brief, as a novice scholar originated from a developing country and moving to Australia to undertake her PhD, the first author was initially overwhelmed by Western schools of thoughts. A milestone for the transformation of her research philosophy was in the first interview with a local authority. During the interview, incongruence between her preassumption, which had been instilled during her immersion in Western orthodoxies through reviewing academic articles in high-ranking journals, and the interviewee's viewpoints emerged. This difference of perspectives forced her to re-think the gap between these two sources of knowing. Accordingly, the terms of "constructivist paradigm", "knowledge co- 
production" came in to elucidate the research process, guide the data analysis and regulate the research outcomes (see further in Ngo, Hales and Lohmann, 2018a).

\section{Lessons adhered to the engagement of multiple voices to co-generate knowledge in a knowledge co-production study}

Along with the implementation of the research process, the principle of power-sharing was practiced. Power sharing is highlighted as one of the advantages of PAR (Liamputtong, 2013). In PAR, the power of legitimate knowledge holders, which is conventionally possessed by researchers, is decentralised to include research participants. Thus, PAR encourages empowerment and confidence among research participants to engage in the research process. Specifically, a knowledge co-production study, framed by PAR principles, advocates for the decolonisation of ways of knowing among co-researchers through their engagement in the research process (Chamber \& Buzinde, 2015). However, translating this attribute into various stages of the research process is a challenge that has repeatedly been raised in knowledge co-production studies (Cornwall, 2004; Pohl et al., 2010).

Accordingly, in our study, various steps were taken to facilitate a sense of fair relations of power and knowledge among research stakeholders. First, in terms of data collection, the interview questions were designed and delivered flexibly to optimise the exploration of respondents' perspectives. They were structured in a basic manner with "How do you think" or "What are your ideas" questions supplemented by "why" questions to clarify the respondents' viewpoints. Additionally, the interview questions were intentionally flexible to make them answerable within the boundaries of all respondents' perceptions. Likewise, in the workshop, the participants were distributed across three concurrent group discussions to ensure that knowledge interactions amplified the voices of marginalised knowledge holders

(e.g., local entrepreneurs, community representatives). Additionally, open-ended survey questions at the end of the workshop encouraged participants to add any ideas that they had not shared during the workshop. Second, regarding the data analysis, the assessment of interview data was independent from Western-driven knowledge. Furthermore, a narrative analysis was employed to explore insights from the respondents' perspectives in accordance with their own way of knowing. Third, the role of the main researcher as a knowledge facilitator rather than a knowledge disseminator was reiterated via different channels of 
communication with each research participant (i.e., during interviews, in emails, in the video and the infographic sent to the workshop participants, and during the workshop). Finally, the research participants were entitled to "read" the research outputs through the video, infographic and presentation briefing illustrating the research findings that were delivered to them. Owing to these techniques, respondents' perspectives were elaborated and justified to engrave valid knowledge values on the topic (see Ngo et al., 2018a; Ngo, Hales, \& Lohmann, 2018b; Ngo, Lohmann \& Hales, 2018).

Along with the democracy of expertise disseminated equitably among research stakeholders, the trustworthiness of data was taken into consideration. This trustworthiness is identified through four criteria, that is, credibility (internal validity), transferability (external validity), dependability (reliability), and confirmability (objectivity) (Shenton, 2004). The strategies recommended by Shenton (2004) to promote the trustworthiness of data in the qualitative research process were applied in our study. For instance, the main researcher was acquainted with the study context (Vietnam) beforehand. The field trip for interviews was prolonged over four months to interview 30 participants. The main researcher constantly implemented reflexivity during the data collection and analysis stages. Data triangulation was achieved as follows: the data collection was undertaken in two stages - interviews and a workshop; the informants were able to check the information after the interviews and workshop; document analysis of the current wealth of knowledge was conducted in conjunction with primary data analysis. The initial data analysis completed by the main researcher was reviewed by the other two researchers (in the role of supervisors), academic fellows (through submitted manuscripts to peer-reviewed publications), and CBTE stakeholders (via the workshop).

Although this study has used the principles of the knowledge co-production approach, it fails to satisfy the attributes of authorship sharing and identification of knowledge holders. Given that the research participants were Vietnamese and their official language was Vietnamese, attribution of authorship was problematic and not addressed in this research. The Australianbased researchers were also confronted with language barriers, as they could not communicate directly with Vietnamese participants. As a compromise, research participants were added to the publications in the acknowledgements section. Development of further 
research methods that seek to facilitate the authorship of research participants of multiple languages within the co-constructed method is warranted.

\section{Conclusion}

This chapter elucidates the knowledge development process incorporated into a knowledge co-production study investigating a collaborative marketing approach for the business sustainability of CBTEs in less-developed countries. The knowledge development process is methodologically underpinned by the three-stage PAR framework developed by Kindon et al. (2007). The research paradigm presented in this chapter illustrates that PAR provides a framework for the attributes of a knowledge co-production approach to be embedded in the stages of the research process. Concurrently, this research paradigm indicates that valuebased knowledge and social learning outcomes can be generated through the involvement of various research stakeholders.

Through depicting the research paradigm and highlighting the lessons drawn from the translation of the abovementioned methodological insights into the research process, this chapter can benefits readers with how to effectively articulate the principles of a knowledge co-production approach and PAR into a study framed by a constructivist approach.

\section{References}

Armitage, D., Berkes, F., Dale, A., Kocho-Schellenberg, E., \& Patton, E. (2011). Comanagement and the co-production of knowledge: Learning to adapt in Canada's Arctic. Global Environmental Change, 21(3), 995-1004.

Barbour, R. (2008). Doing focus groups. London: Sage.

Becken, S., Zammit, C., \& Hendrikx, J. (2015). Developing Climate Change Maps for Tourism: Essential Information or Awareness Raising? Journal of Travel Research, 54(4), 430-441.

Berkes, F. (2009). Evolution of co-management: role of knowledge generation, bridging organizations and social learning. Journal of environmental management, 90(5), 1692-1702. 
Carr, A., Ruhanen, L., \& Whitford, M. (2016). Indigenous peoples and tourism: the challenges and opportunities for sustainable tourism. Journal of Sustainable Tourism, 24(8-9), 1-13.

Castleden, H., Morgan, V., \& Lamb, C. (2012). “I spent the first year drinking tea”: Exploring Canadian university researchers' perspectives on community-based participatory research involving Indigenous peoples. The Canadian Geographer/Le Géographe Canadien, 56(2), 160179.

Chambers, D. \& Buzinde, C. (2015). Tourism and decolonisation: Locating research and self. Annals of Tourism Research, 5, 1-16.

Cole, S. (2006). Information and empowerment: The keys to achieving sustainable tourism. Journal of Sustainable Tourism, 14(6), 629-644.

Cornwall, A. (2004). Spaces for transformation? Reflections on issues of power and difference in participation in development. In S. Hickey \& G. Mohan (Eds), Participation - from tyranny to transformation? Exploring new approaches to participation in development (pp. 75-91). London: Zed Books.

Dale, A., \& Armitage, D. (2011). Marine mammal co-management in Canada's Arctic: knowledge co-production for learning and adaptive capacity. Marine Policy, 35(4), 440-449.

Davidson-Hunt, I. J., \& Michael, O. R. (2007). Researchers, indigenous peoples, and placebased learning communities. Society and Natural Resources 20(4), 291-305

Dixey, L. M. (2008). The unsustainability of community tourism donored projects: Lessons from Zambia. In A. Spenceley (Ed.), Responsible tourism: Critical issues for conservation and development (pp.323-342). London: Earthscan.

Dodds, R., Ali, A., \& Galaski, K. (2016). Mobilizing knowledge: Determining key elements for success and pitfalls in developing community-based tourism. Current Issues in Tourism, 1-22.

Dredge, D. \& Jamal, T. (2015). Progress in tourism planning and policy: A post-structural perspective on knowledge production. Tourism Management, 51, 285-297. 
Espeso-Molinero, P., Carlisle, S., \& Pastor-Alfonso, M. J. (2016). Knowledge dialogue through Indigenous tourism product design: a collaborative research process with the Lacandon of Chiapas, Mexico. Journal of Sustainable Tourism, 24(8-9), 1331-1349.

Font, X. \& McCabe, S. (2017). Sustainability and marketing in tourism: its contexts, paradoxes, approaches, challenges and potential. Journal of Sustainable Tourism, 25(7), 869-883.

Goodwin, H., \& Santilli, R. (2009). Community-based tourism: A success. ICRT Occasional Paper, 11(1), 1-37.

Guba, E. G. (1990). The paradigm dialog. Newbury Park, CA: Sage Publications.

Guba, E. G., \& Lincoln, Y. S. (1994). Competing paradigms in qualitative research. Handbook of qualitative research, 2(163-194), 105.

Hollinshead, K. (2006). The shift to constructivism in social inquiry: Some pointers for tourism studies. Tourism Recreation Research, 31(2), 43-58.

Holmes, A. P., Grimwood, B.S.R., King, L.J, \& Lutsel, K.D.F.N. (2016). Creating an Indigenized visitor code of conduct: The development of Denesoline self-determination for sustainable tourism. Journal of Sustainable Tourism, 24(8-9), 1177-1193.

Idziak, W., Majewski, J., \& Zmyślony, P. (2015). Community participation in sustainable rural tourism experience creation: a long-term appraisal and lessons from a thematic villages project in Poland. Journal of Sustainable Tourism, 23(8-9), 1341-1362.

Jamal, T. \& Watt, E. M. (2011). Climate change pedagogy and performative action: Toward community-based destination governance. Journal of Sustainable Tourism, 19(4-5), 571-588.

Jennings, G. (2010). Tourism research, 2nd edition. Milton: John Wiley \& Sons Australia Ltd.

Kindon, S., Pain, R., \& Kesby, M. (2007). Participatory action research approaches and methods: Connecting people, participation and place. New York: Routledge.

Krueger, R. A. \& Casey, M. A. (2014). Focus groups: A practical guide for applied research. California: SAGE Publications. 
Liamputtong, P. (2013). Qualitative research methods. Melbourne: Oxford University Press.

Maiello, A., Viegas, C. V, Frey, M., \& Ribeiro, D. (2013). Public managers as catalysts of knowledge co-production? Investigating knowledge dynamics in local environmental policy. Environmental Science \& Policy, 27, 141-150.

Marshall, N., Viegas, C.V., Frey, M., \& Ribeiro, J.L.D (2016). Advances in monitoring the human dimension of natural resource systems: an example from the Great Barrier Reef. Environmental Research Letters, 11(11), 141-150.

Mbaiwa, J. E., Stronza, A., \& Kreuter, U. (2011). From collaboration to conservation: insights from the Okavango Delta, Botswana. Society \& Natural Resources, 24(4), 400-411.

Mielke, E. J. C. (2012). Community based tourism: Sustainability as a matter of result management. In G. Lohmann \& D. Dredge (Eds.), Tourism in Brazil (pp. 30-43). London: Taylor \& Francis.

Ngo, T, Hales. R \& Lohmann. G (2018a). Social learning of co-researchers in a knowledge coproduction study. Paper presented at The Council for Australasian Tourism and Hospitality Education CAUTHE 28 ${ }^{\text {th }}$, Newcastle, Australia.

Ngo, T., Hales, R., \& Lohmann, G. (2018b). Collaborative marketing for the sustainable development of community-based tourism enterprises: Reconciliation of diverse perspectives. Current Issues in Tourism, 1-18.

Ngo, T., Lohmann, G., \& Hales, R. (2018). Collaborative marketing for the sustainable development of community-based tourism enterprises: voices from the field. Journal of Sustainable Tourism, 26(8), 1325-1343.

Nowotny, H. (2003). Democratising expertise and socially robust knowledge. Science and Public Policy, 30(3), 151-156.

Pohl, C., Rist, S., Zimmermann, A., Fry, P., Gurung, G. S., Schneider, F., ... Serrano, E. (2010). Researchers' roles in knowledge co-production: experience from sustainability research in Kenya, Switzerland, Bolivia and Nepal. Science and Public Policy, 37(4), 267-281. 
Reason, P. \& Bradbury. H. (2008). The Sage handbook of action research participative inquiry and practice. London: SAGE Publications.

Rocharungsat, P. (2008). Community based tourism in Asia. In Moscardo, G. (Ed.). Building community capacity for tourism development. Wallingford: CABI Publishing.

Ross, H., Shaw, S, Rissik, D, Cliffe, N., Chapman, S., Hounsell, V., ... Schoeman, J. (2015). A participatory systems approach to understanding climate adaptation needs. Climatic Change, 129(1-2), 27-42.

Shenton, A. K. (2004). Strategies for ensuring trustworthiness in qualitative research projects. Education for information, 22(2), 63-75.

Torres-Delgado, A. \& Saarinen, J. (2014). Using indicators to assess sustainable tourism development: a review. Tourism Geographies, 16(1), 31-47.

Ungar, P. \& Strand, R. (2012). Inclusive protected area management in the Amazon: The importance of social networks over ecological knowledge. Sustainability, 4(12), 3260-3278.

Weiss, K., Hamann, M., \& Marsh, H. (2013). Bridging knowledge: understanding and applying indigenous and western scientific knowledge for marine wildlife management. Society \& Natural Resources, 26(3), 285-302. 